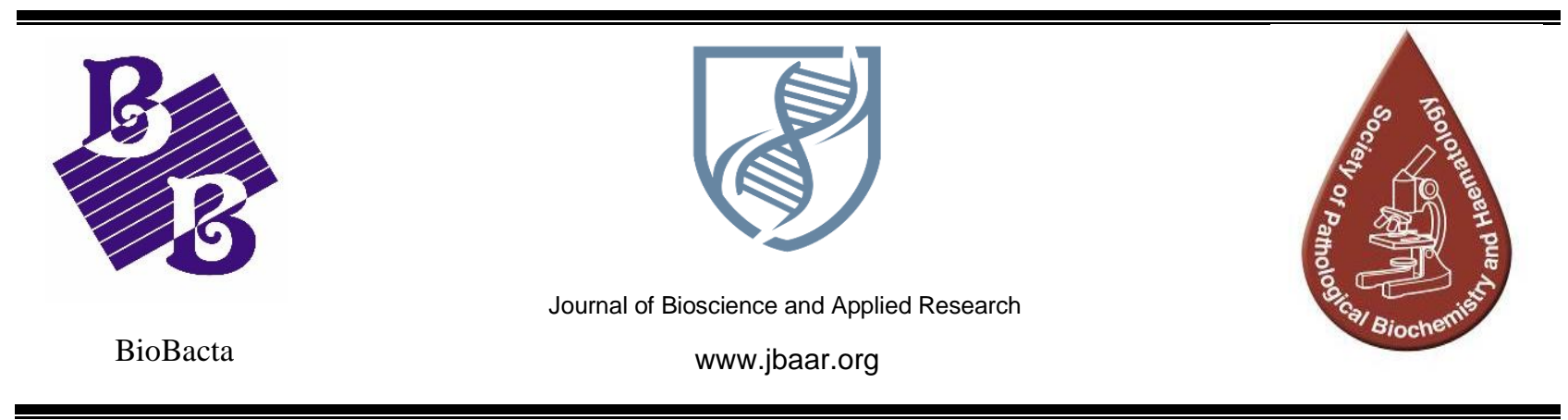

\title{
Characterization and anti-inflammatory activity effect of exopolysaccharide from Bacillus axarquiensison paw rats carrageenan model
}

\author{
Ghada S. Ibrahim*1,2, Manal G. Mahmoud ${ }^{1}$, Mohamed E. EL Awady ${ }^{1}$ Mahgoub M \\ Ahmed ${ }^{3}$ and Samah A Fathy ${ }^{3}$
${ }^{1}$ Microbial Biotechnology Department, Genetic Engineering and Biotechnology Research Division, National Research Centre, 33 Bohouth St., Dokki, Giza, 12622, Egypt.
${ }^{2}$ Department of Biochemistry, College of Science, University of Jeddah, Jeddah, Saudi Arabia.
${ }^{3}$ Molecular Drug Evaluation Department, National Organization for Drug Control and Research (NODCAR), Giza, Egypt
*Correspondence: bekhit101@yahoo.com
DOI: 10.21608/jbaar.2019.115568

\begin{abstract}
The exopolysaccharide (EPS) was produced by a halophilic bacterial strain isolated from marine sediments, Porto-Elsokhna Beach, Egypt. This isolate has been defined morphologically and physiologically and has been recognized by $16 \mathrm{~S}$ rDNA as Bacillus axarquiensis NRC G6.This strain was deposited in the Gene Bank (http://www.ncbi.nlm.nih. gov) under the accession number of KU945823. The EPS produced was fractionated by precipitation and listed the primary fraction as EPSBa3. Through FT-IR and HPLC, further work attempted to elucidate the structural function of EPSBa3. The findings showed that EPSBa3 was an acidic EPS composed of glucuronic: mannose: galacturonic: glucose and xylose, respectively, in a molar ratio of 1:1:3:3:3. The proportion of uronic acid and sulfate was $13.9 \%$ and $7 \%$ respectively. The estimated median molecular weight (Mw) and molecular number $(\mathrm{Mn})$ were $1.499 \times 10^{6}$ and $1.29 \times 10^{6} \mathrm{~g} / \mathrm{mol}$. In rats, the antiinflammatory activity of exopolysaccharide (EPSBa3) was also explored using paw edema induced by carrageenan. EPSBa3 caused important anti-inflammatory effects on the carrageenan model by $50 \mathrm{mg} / \mathrm{kg}$ orally. In catalase (CAT) and superoxide dismutase (SOD) enzymes and GSH content, the EPSBa3 enhanced declines. In addition, the content of nitric oxide (NO), lipid peroxidation (LPO) and reactive oxygen species (ROS) arising from carrageenan-induced edema were considerably reduced following therapy with EPSBa3. In addition, the findings showed that interleukin-6 (IL-6) protein expression was decreased after EPSBa3 treatment leading to alleviate paw edema. These findings stated that to avoid inflammatory diseases, EPSBa3 could be utilized as a source of natural products.
\end{abstract}

\section{Keywords:}

Bacillus axarquiensis; exopolysaccharide, oxidative stress, carrageenan, and anti-inflammatory activity.

Received 20/9/2019; Accepted 25/10/2019 


\section{Introduction}

Marine environmental circumstances are generally distinct from terrestrial circumstances, which could confer distinctive features on marine microorganisms, enabling them to create various new biologically active compounds $(1,2)$. The isolation of fresh microorganisms is a significant feature for taxonomy, production and function identification (3). The marine environment (Egypt's Porto-Elsokhna beach) could be viewed as a repository of many novel microorganisms that have the capacity to generate polysaccharide particular to secondary metabolites $(4,5)$. The polymers excreted by some microorganisms are known as exopolysaccharides (EPS) as protective obstacles against damaging circumstances. Bacillus axarquiensis is one of the most widespread fleshy bacteria of the species bacilli and can be isolated from all nations. Many microbial EPS can be used in a broad spectrum of biotechnological applications, such as stabilizers, thickeners, and texturizers in the food industry, antiaging molecules in the cosmetics sector, or flocculating agents in the sewage treatment sector (68). The EPS also contributes to multiple human physiological operations as an antioxidant, antitumor, anti-viral (9) and anti-inflammatory agents and can behave as inducers of interferon, platelet aggregation inhibition and colony-stimulating factor synthesis (10-13). Extremely variable salinity, temperature and pressure conditions are described in marine settings. Thus, the bacteria that are isolated from these settings are anticipated to vary in adaptation mechanisms compared to worldwide ones, such as the synthesis of EPS with individual components and different compositions that permit ongoing life there. This variety is one of the excellent concerns nowadays because it provides the chance of finding new molecules with exclusive characteristics, such as antibacterial, algaecide or anti-fouling operations (14-16). As a consequence of the study of several marine species producing EPS, novel macromolecules were found and isolated (17). Most marine-derived EPS are bacterial (i.e., mesophilic and heterotrophic classical bacteria; psychrophilic, thermophilic and halophilic extremophilic microorganisms); archaea have also been shown to generate EPS (17-19). Bacillus sp. a significant group of bacteria that has several benefits over other bacteria, such as simple cultivation and conservation, and is therefore conducive to industrial production (20). Bacillus sp. can generate more EPS than lactic acid bacteria, and more than one form of EPS may be produced by the same Bacillus strain (21). In addition, their immune-modulating and anti-cancer impacts are the most promising biological characteristics of these polysaccharides. A possible mechanism is that it is suggested that these polysaccharides improve in vivo and in vitro cellmediated immune responses and act as modifiers of biological reaction. In addition, polysaccharide's antiinflammatory activities were also researched in these years. Du et al., (2015) (22) assessed the fungal betaglucan (a type of polysaccharide) anti-inflammatory effects. A beta-glucan from Alcaligenes faecalis was discovered to be able to induce CD4 (+) T cells producing IL-10 and to inhibit the growth of Eosinophilic airway inflammation (23). In addition, Du et al. (2016) (24) discovered S polysaccharide's anti-inflammatory activity. Ultrasonic therapy affected the municipality. It has been suggested that polysaccharide's powerful anti-inflammatory activity, potentially due to pro-inflammatory cytokine inhibition or enhanced anti-inflammatory cytokine manufacturing (25). In the present study was to purify and characterize the Bacillus axarquiensis exopolysaccharide by high performance liquid chromatography (HPLC) and Fourier transform infrared spectroscopy (FT-IR), Also its antiinflammatory effects were evaluated after isolating and identifying the bacterial strain by $16 \mathrm{~S}$ rDNA,. For exploring the application of the EPS as a functional ingredient in the food industry.

\section{Materials and methods}

\section{Chemicals}

Reduced glutathione, 1-chloro-2,4-dinitrobenzene (CDNB), thiobarbituric acid (TBA) and $\lambda$ carrageenan, type IV were obtained from Sigma 
Chemical (St Louis, USA). All other chemicals and reagents used were of analytical grade.

\section{Sample and culture medium}

Sea sediment samples were collected from PortoElsokhna beach in Egypt. The sediments were collected at depths of 2-3 m. A medium composed of (g/l): 20, agar; 20, sucrose; 2, yeast extract and 4, peptone was used for isolation, purification, and short-time storage. The medium was prepared with natural seawater collected on-site and distilled water in the proportion of 75:25 (v/v).

Isolation of bacterium producing the EPS

The samples were processed using the following method: wet sediment $(1 \mathrm{~g})$ was diluted with $100 \mathrm{~mL}$ of sterile seawater (SSW). After mixing, the diluted sample was allowed to settle for a few minutes, and then serially diluted. One $\mathrm{ml}$ of each dilution was spread on the agar plate medium. Petri dishes were incubated at $37^{\circ} \mathrm{C}$ and observed occasionally for bacterial growth. The colonies on the plates were purified acceding to the streak plate method (26) and the purified isolates were inoculated on the agar medium and incubated at $37^{\circ} \mathrm{C}$ for 5 days.

\section{Screening of EPS producing strain}

Thirty colonies of strains exhibited shiny and slimy surfaces on the growth media. It indicates the production of EPS by bacteria (27). The strains were regularly subculture and sustained in nutrient agar slants as stock. The strains were cultivated in $25 \mathrm{~mL}$ shake flasks on liquid medium containing per liter ( $750 \mathrm{~mL}$ sea water and $250 \mathrm{~mL}$ distilled water): $20 \mathrm{~g}$ sucrose, $2 \mathrm{~g}$ yeast extract, and $4 \mathrm{~g}$ peptone. The cultures were incubated in a shaker, for 3 days, at $37^{\circ} \mathrm{C}$ and $120 \mathrm{rpm}$. The culture medium was centrifuged at $5000 \mathrm{rpm}$ for $30 \mathrm{~min}$ to remove cells; the supernatant was further subjected to deproteinization by TCA 5\% (28). The yield of EPS was determined by the phenol- $\mathrm{H}_{2} \mathrm{SO}_{4}$ method using glucose as standard (29). The EPS was precipitation by addition 5 volume absolute ethanol and collected by centrifuged at $5000 \mathrm{rpm}$ for $20 \mathrm{~min}$ at $4{ }^{\circ} \mathrm{C}$, the precipitate was washed by acetone and dried under vacuum.

\section{Identification of screened strain}

Morphological and Physiological
Characterization

The most potent bacterial strain was identified by its morphological, physiological and biochemical experiments according to Bergey's Manual of Determinative Bacteriology (30). The identification was confirmed by comparing the results of a morphological shape, Gram's staining, growing tests at different temperatures and $\mathrm{pH}$, catalase tests.

\section{S rDNA sequence identification}

The extraction of DNA was carried out by a DNA extraction Kit and quality was evaluated on $1.2 \%$ agarose gel, a single band of high Mw DNA has been observed. The forward primer was ITS1 (5'TCCGTAGGTGAAC TTTGCGG-3') and the reverse primer was ITS4 (5'TCCTCCGCTTATTGAT ATGC-3')(31). The PCR amplified was purified to remove contaminants. Forward and reverse DNA sequencing reaction of PCR amplified was carried and then performs 35 amplification cycles at $94^{\circ} \mathrm{C}$ or $45 \mathrm{~s}, 55^{\circ} \mathrm{C}$ for $60 \mathrm{~s}$ and $72^{\circ} \mathrm{C}$ for $60 \mathrm{~s}$. DNA fragments are amplified about $988 \mathrm{bp}$ in the case of bacteria. Include a positive control (E. coli genomic DNA) and negative control in the PCR. Sequencing was performed by using Big Dye terminator cycle sequencing kit (Applied Biosystems, USA). Sequencing products were resolved on an Applied Bio-systems model 3730XL automated DNA sequencing system. The forward and reverse 16S rDNA sequences obtained were checked for accurate base calling, assembled and analyzed using BLAST available on the NCBI website (http://www.ncbi.nlm.nih.gov). A neighborjoining phylogenetic tree was constructed from 1630 bp using the Clustal X version 2 with 1000 bootstrap replicates (32).

\section{Isolation and fractionation of EPS}

EPS was separated from the culture medium by centrifuged at $5000 \mathrm{rpm}$ for $30 \mathrm{~min}$ to remove cells; 
the supernatant was subjected to deproteinization by TCA 5\% (28). After that EPS was precipitated by adding 5 volumes of cold ethanol. The resulted precipitate was centrifuged, re-dissolved in the deionized water and dialyzed against water for 3 days at $4{ }^{\circ} \mathrm{C}$. The supernatant was centrifuged again to remove the insoluble materials and then fractionated using 1, 2, 3 and 4 volumes cold absolute ethanol. The white fractions powder was obtained for further work (33).

\section{Chemical analysis}

Total sugars were determined by the phenol$\mathrm{H}_{2} \mathrm{SO}_{4}$ method (29) Dubois et al., 1956 using glucose as standard. Uronic acid was measured by the $\mathrm{m}$ hydroxybiphenyl method (34), using glucuronic acid as standard. Sulfate was determined after hydrolysis (formic acid $85 \%$ at $100^{\circ} \mathrm{C}, 5 \mathrm{~h}$ ) using the turbidimetric method (35) with sodium sulfate as standard. A monosaccharides composition of the main fraction (EPS) was determined by highperformance liquid chromatography (HPLC). About $200 \mathrm{mg}$ was hydrolyzed with $2 \mathrm{~mL}$ of formic acid $85 \%$ at $100^{\circ} \mathrm{C}$ in a sealed tube for $12 \mathrm{~h}$. The plenty of acid was removed by flash evaporation on a water bath at a temperature of $50^{\circ} \mathrm{C}$ and co-distilled with water $(1 \mathrm{~mL} \times 4)$ and then evaporated to dryness (36). The monosaccharides contents were quantified by HPLC on a Shimadzu Shim-Pack SCR-101N column $(7.9 \mathrm{~mm} \times 30 \mathrm{~cm})$, using deionized water as the mobile phase at flow rate $0.5 \mathrm{~mL} / \mathrm{min}{ }^{\circ} \mathrm{C}$ (37). The identification of sugar was done by comparison with authentic sugars.

\section{Molecular weight analysis}

The weight-average molecular weight $(M w)$ and number-average molecular weight $(M n)$ of EPS were determined on an Agilent 1100 HPLC system equipped with a RI Detector. The EPS was dissolved in $2 \mathrm{~mL}$ of solvent and then it filtrated through a 0.45 $\mu \mathrm{m}$ filter prior to injection. The polydispersity index (PI) calculated from the $M w / M n$ ratio $(38,39)$.

\section{The FT-IR spectrum of EPS}

The FTIR spectrum of EPS was determined using a Bucker scientific 500-IR FTIR spectrophotometer (Bucker Co., Ettlingen, Germany) at a range of 4000$400 \mathrm{~cm}^{-1}$. The purified EPS was ground with spectroscopic grade $\mathrm{KBr}$ powder and then pressed into pellets for FTIR measurement (40).

\section{Experimental Animals}

Male albino rats $(160 \pm 20 \mathrm{~g})$ from the laboratory stock colony of National Organization for Drug Control and Research (NODCAR) were used in the present study. The animals were kept under normal environmental conditions for one week before the initiation of the experiment. The animals were allowed free access to water and were fed on a basal diet. The animals were kept individually in stainless steel cages at air condition $20-22{ }^{\circ} \mathrm{C}$ and relative humidity of about $55 \%$.

\section{Anti-inflammatory activity of EPS}

Thirty-six male albino rats were divided into six groups each comprised of six rats. Before any treatment, the thickness of the back paw of each animal was determined using an electronic digital caliper, Germany. EPS samples were prepared by dissolving them in d water. Rats were administered orally with EPS at dose $50 \mathrm{mg} / \mathrm{kg}$, One hour after these administrations, each rat received in its left back paw a sub planter injection of $1 \%$ carrageenan suspension (0.1 ml per animal) (41). The thickness of the back paw of each rat was measured at 1, 2, 34 and 5 hours after the injection of the carrageenan.

\section{Biochemical investigation}

Two grams of paw tissues were taken, rinsed in icecold distilled water and immediately placed in three times their volume of cold $1.15 \% \mathrm{KCl}$ containing $0.2 \%$ Triton X-100 and homogenized. The homogenate was centrifuged at $8000 \mathrm{~g}$ for $10 \mathrm{~min}$ to obtain the supernatant stored at $-20^{\circ} \mathrm{C}(42)$.

\section{Determination of oxidative stress parameters} Measurement of malondialdehyde (MDA)

MDA content was assayed using the thiobarbituric acid (TBA) test as described by 
Ohkawa et al., 1979 (43). MDA reacts with TBA to form a colored complex. Absorbance was measured at $532 \mathrm{~nm}$ to determine the MDA content. The specific activity is defined as $\mathrm{nm} / \mathrm{g}$ tissue.

\section{Measurement of reactive oxygen species (ROS) content}

ROS was estimated according to Vrablic et al.,2001 (44). A modified version of a previously described assay for the intracellular conversion of nitro blue tetrazolium (NBT) to formazan by superoxide anion was used to measure the generation of reactive oxygen species

\section{Measurement of Nitric Oxide}

NO was estimated according to Wang et al., (2002) (45) using Griess reaction. Briefly, to an aliquot of supernatants, Griess reagent was added and the colored product formed was read at $540 \mathrm{~nm}$. NO was quantified using a standard curve.

\section{Determination of reduced glutathione (GSH)}

Levels of GSH were assayed by the method of Beutler et al. (1963) (46). Briefly, the deproteinization of homogenate was made by $10 \%$ trichloroacetic acid and centrifuged at $3500 \mathrm{rpm}$ for $10 \mathrm{~min} .50 \mu \mathrm{L}$ supernatant was mixed with $0.32 \mathrm{~mol} / \mathrm{L}$ disodium hydrogen phosphate and $0.04 \%$ 5,5'dithiobis 2-nitrobenzoic acid (DTNB) solution. The yellow-colored substance formed by the reaction of GSH and DTNB was measured at $412 \mathrm{~nm}$. The results were expressed as GSH mmol/g tissue.

\section{Determination of Superoxide dismutase (SOD) activity}

Superoxide dismutase (SOD) activity in kidney homogenate was determined according to the method of Minami and Yoshikawa (1979) (47). This method is based on the generation of superoxide anions by pyrogallol autoxidation, detection of generated superoxide anions by nitro blue tetrazolium (NBT) formazan color development and measurement of the amount of generated superoxide anions scavenged by
SOD (the inhibitory level of formazan color development). SOD activity is expressed as $\mathrm{U} / \mathrm{g}$ tissue.

\section{Measurement of catalase (CAT)}

The CAT activity was measured according to the method described by Aebi (1984) (48) by assaying the hydrolysis of $\mathrm{H}_{2} \mathrm{O}_{2}$ and the resulting decrease in absorbance at $240 \mathrm{~nm}$ over a 3 min period at $25^{\circ} \mathrm{C}$. CAT activity is expressed as $\mathrm{mmol} / \mathrm{g}$ tissue.

\section{Protein expression of IL-6}

IL-6 contents were analyzed using a commercially available ELISA kit (BioSource International, Inc., Camarillo, CA, USA) according to the instructions of the manufacturer in the supernatant.

\section{Statistical analysis}

Statistical analyses were performed with SPSS software and were calculated using one-way ANOVA followed by Post Hoc Duncan. $\mathrm{P}<0.05$ was considered to indicate a statistically significant result.

\section{Results and Discussion}

Isolation, screening, and identification of the bacteria-producing EPS Thirty strains from a total of seventy single colonies were chosen from separate marine specimens based on their morphological variations in agar plates. Finally, G6 strain was selected as one of the best EPS' producers according to the yield of polysaccharide per liter $(2.6 \mathrm{~g} / \mathrm{L})$. The most powerful bacterial isolate G6 was recognized with morphological and physiological features on a molecular basis (16s rDNA). With 99 percent resemblance to Bacillus axarquiensis NRC G6, G6 was discovered to belong to the genus Bacillus. The nucleotide sequence was placed under the KU945823 accession number in the GeneBank (http:/www.ncbi.nlm.nih. gov). Table (1) and Fig. (1), respectively, show morphological and physiological features along with the phylogenetic tree of Bacillus axarquiensis. 
Table 1.Morphological, cultural and physiological characteristics of G6 isolate

\begin{tabular}{|l|l|}
\hline Character & Result \\
\hline Gram's stain & Positive \\
\hline Spore formation & Endospore forming \\
\hline Cell shape & round-ended rods -shaped \\
\hline Motility & Motile \\
\hline Colony shape & $\begin{array}{l}\text { the colonies are cream-coloured, slightly irregular in } \\
\text { shape and bulge upward }\end{array}$ \\
\hline Oxygen requirement & Aerobic \\
\hline pH and salinity & Haloalkaliphilic \\
\hline Catalase production & Positive \\
\hline
\end{tabular}

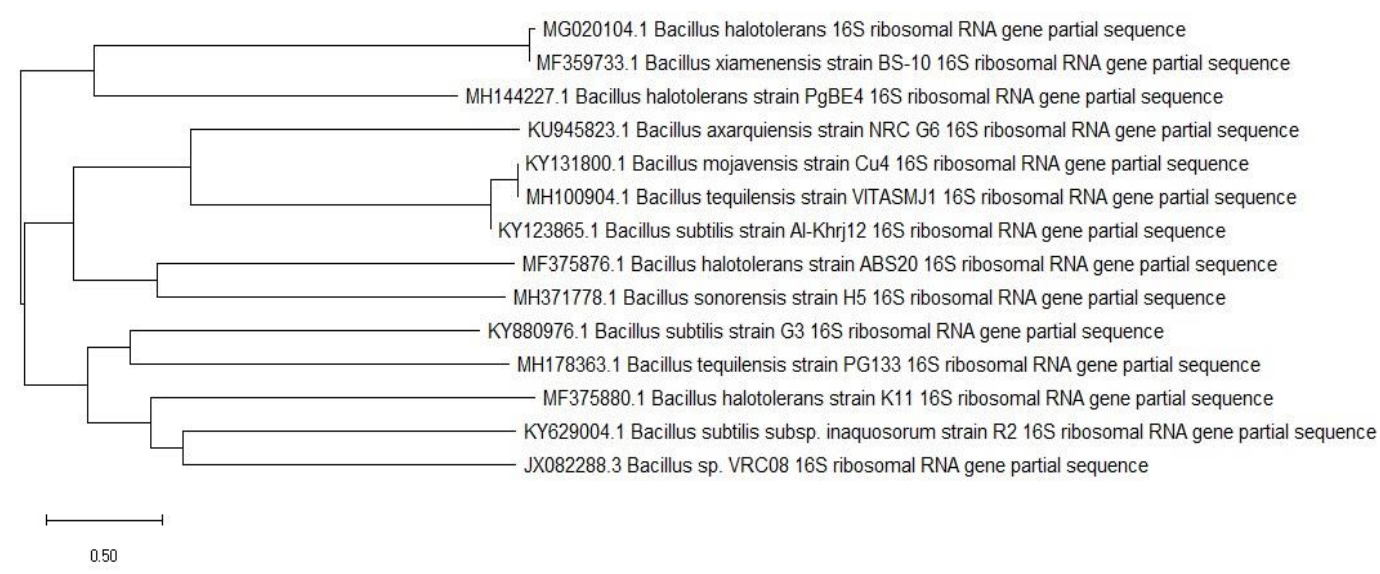

Figure 1. Phylogenetic tree based on $16 \mathrm{~S}$ rDNA gene sequencing, showing the phylogenetic relationship of Bacillus axarquiensis within representative species of the genus Bacillus

\section{EPSBa3 isolation and chemical structure}

Many marine bacteria, such as Edwardsiella tarda, Paenibacillus polymyxa and Alteromonas, could generate EPSs (49). Bacillus axarquiensis NRC G6's EPS output was $2.6 \mathrm{~g} / 1$ of medium development after 5 days. After fractionation with ethanol precipitation from crude EPS, the primary fraction EPSBa3 was achieved. The EPSBa3 has been gathered for further structural assessment. It emerged as a white-yellow powder, with the Bradford test having an adverse response. The data that the UV spectra did not detect absorption at 260 and $280 \mathrm{~nm}$ stated that RNA, DNA and/or protein were not present. EPSBa3 contained $13.9 \%$ uronic acid as assessed by colorimetric m-hydroxydiphenyl and 7\% sulfate. HPLC determined the structure of 
monosaccharides of EPSBa3 hydrolysate, in which glucuronic: mannose: galacturonic: glucose and xylose were recognized in the hydrolysate and their molar proportions were 1:1:3:3:3, respectively. Smiderle, et al. (2008) and Silveiraet al. (2015) $(50,51)$ were found to have a marked antinociceptive impact when tested in mice, showing that mushroom heteropolysaccharides may also have therapeutic characteristics such as anti-inflammatory activity. The EPSBa3's Mw, Mn and polydispersity index (PI) was evaluated by chromatography of gel permeation. The EPSBa3 was widely dispersed (PI) 1.16 in the GPC chromatogram and had a total $\mathrm{Mw}$ of 1.499 $\mathrm{X} 10^{6} \mathrm{~g} / \mathrm{moL}$ and Mn of 1.29 X $10^{6} \mathrm{~g} / \mathrm{moL}$ (Fig.2). Bacillus sp.1-450's molecular weight of EPS was $2.2103 \mathrm{KDa}$ and the functional groups in the EPS chains are key determinants for biological operations (52). Sulfate groups are generally not found in microorganism EPSs, whereas they are found in all halophilic bacterial EPSs and in several marine bacterial EPSs and brown and red algae PSs in cell walls (53-56).
Sulfated EPSs are of large potential interest in medicine because they have a number of bioactive properties $(57,58)$. Band intensity at 3855.97 and $3432.67 \mathrm{~cm}-1$ bands showed $\mathrm{OH}$ axial deformation that matched the intermolecular and intermolecular hydrogen bond $(59,60)$. The soft band for the secondary and primary (CH2) bands at $2934.16 \mathrm{~cm}^{-1}$ were ascribed to the axial deformation of the $\mathrm{CH}$ (61$60)$. New bands emerged in the area of $1644.98 \mathrm{~cm}-1$ correspondings to the stretching vibration of $\mathrm{C}-\mathrm{O}$ and $\mathrm{COO}$ groups. $\mathrm{CH} 2$ and $\mathrm{OH}$ bonding (Fig. 3) were depicted by the absorptions around $1433.82 \mathrm{~cm}-1$. Strong absorption at $1261.22 \mathrm{~cm}-1$ was subjugated by vibration-stretching glycosidic linkage $(\mathrm{C}-\mathrm{O}-\mathrm{C})$ (62). In addition, the glucosyl residue B-pyranose shape was stated by the band at $928.56 \mathrm{~cm}^{-1}$. The FT-IR assessment, therefore, proposed that the EPSBa3 could very well belong to the B-anomeric setup (63).

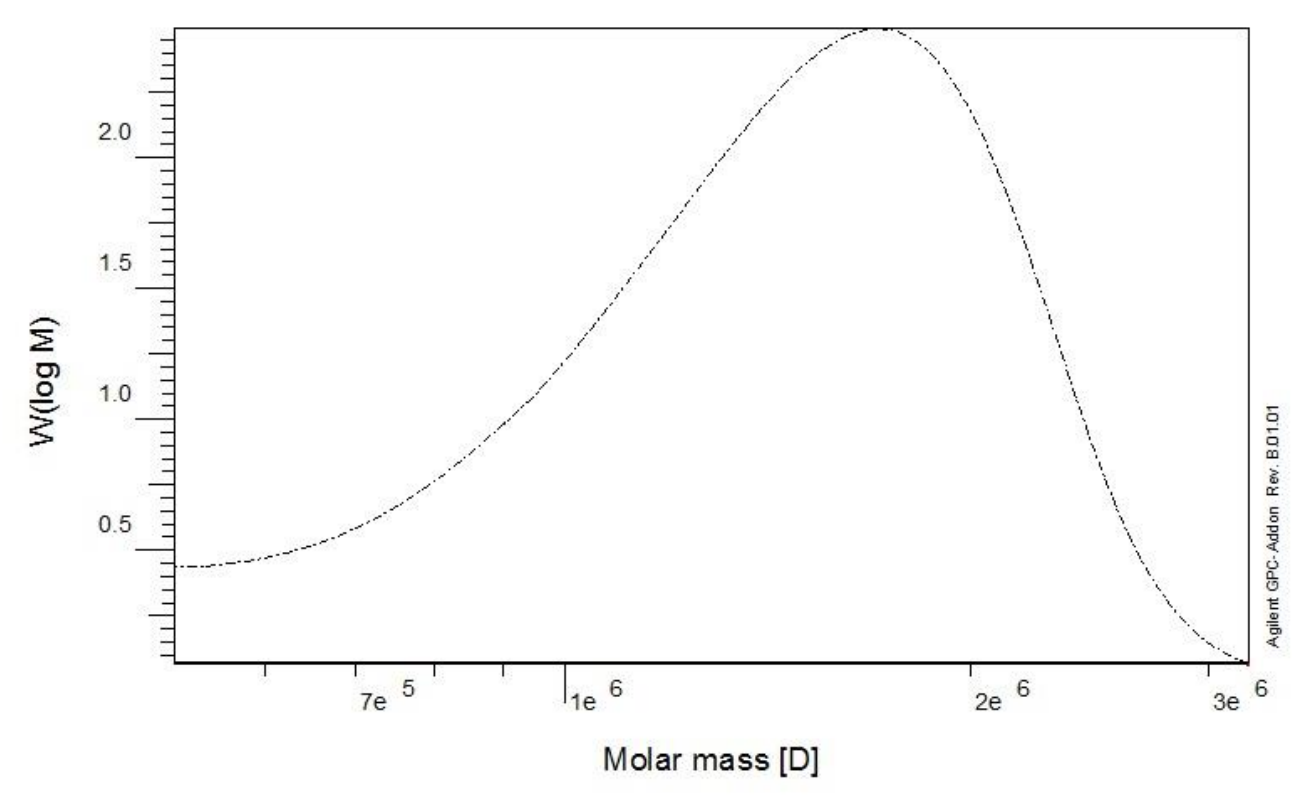

Figure 2. Molecular weight distribution of EPS Ba3 from Bacillus axarquiensis 


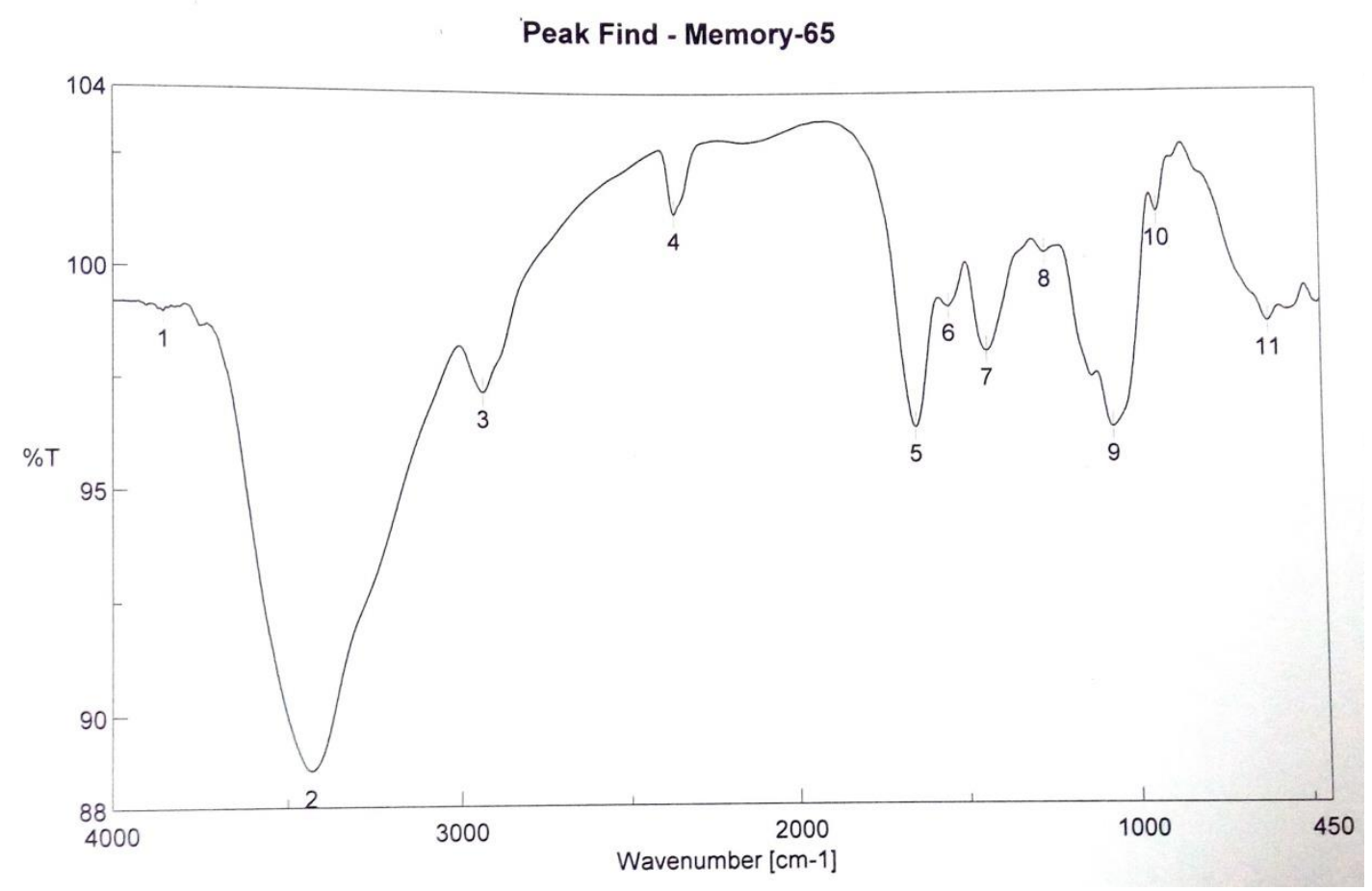

Figure 3. FT-IR spectrum of EPSBa3 from Bacillus axarquiensis NRC G6

\section{Antioxidant activity}

EPSBa3's antioxidant activity at distinct levels $(200,400,600,800$ and $1000 \mu \mathrm{g} / \mathrm{ml})$ was assessed as free radical DPPH scavenging and its outcomes are shown in Figure (4). It is evident that the largest scavenging activity for EPSBa3 was discovered at $1000 \mu \mathrm{g} / \mathrm{ml}$ for $60 \mathrm{~min}$. followed by $1000 \mu \mathrm{g} / \mathrm{ml}$ (91.3\%), $45 \mathrm{~min}$. (90.9\%), $800 \mu \mathrm{g} / \mathrm{ml}$ for $60 \mathrm{~min}$. (85.8\%) for $45 \mathrm{~min}$. and $1000 \mu \mathrm{g} / \mathrm{ml}(84.5 \%)$ for 30 min. In diminishing order. The EPSBa3 was discovered to have DPPH radical-scavenging activity with an IC50 value of $400 \mu \mathrm{g} / \mathrm{ml}$ in the in vitro antioxidant assay. The findings are comparable to those of Zhang et al., (64) who discovered that the sulfated galactan fraction F1 (isolated from red seaweed, Porphyrahaitanensis) had substantial in vitro antioxidant activity, Seng et al., (65) discovered that polysaccharide extracts from Ganodermatsugae had excellent antioxidant characteristics except for their capacity to scavenge against hydroxyl radicals and could be good candidates. As a fresh dietary supplement and functional food, Asker et al., (66) assessed the radical scavenging assay (RSA) antioxidant activity of CPS, CPSI, and CPSII in vitro. CPSI fraction showed the greatest antioxidant activity among the three fractions, EPS analysis showed elevated antioxidant activity and this could explain the pharmacological foundation for ill avoidance, inflammation, and atherosclerosis of polysaccharides (67).

\section{Anti-inflammatory activity}

Inflammation is the body's complicated biological reaction to diseases, irritations or other wounds, and harm to cells. Inflammation plays a significant role in multiple illnesses such as rheumatoid arthritis, asthma, inflammatory intestinal disease, neurodegenerative illnesses, and cancer (68). Several pro-inflammatory mediators, including IL-6, IL-12, TNF, COX-2 and inducible nitric oxide synthase (iNOS) are published during an inflammatory reaction (69). We examined the in vitro antiinflammatory impact of EPSBa3 in rats using the carrageen-induced paw edema model in this research. 
Carrageen-induced paw edema is a model commonly used to screen anti-inflammatory drug impacts (70).

Effect of EPSBa3 on carrageenan-induced paw edema in rats Paw thickness was improved in a timedependent way following carrageenan injection in rats (Table 2). Carrageenan administration improved paw thickness at 1 hour and was maximum after 5 hours. However, after therapy with carrageenan, paw edema $(\mathrm{P}<0.05)$ was considerably decreased after therapy with EPSBa3 at 3, 4 and $5 \mathrm{~h}$ (Table 2).

The current research shows that EPS plays an important role as a protective agent against the growth of acute inflammation induced by carrageenan. The formation of edema in the paw is the consequence of a synergy between multiple inflammatory mediators that increases lung permeability and/or blood flow mediators (71). Inflammatory processes are the organism's physiological reaction to various stimuli such as trauma, diseases or mechanisms of immunology. During inflammation, the arachidonic acid cascade is extremely activated, leading in eicosanoid formation, and it is mediated by cyclooxygenase and5lipoxygenase enzymes (72). It is thought that carrageenan-induced rat paw edema is biphasic. The first stage $(1 \mathrm{~h})$ includes the release of histamine and serotonin and the second stage (more than 1 hour) is due to the release of drugs similar to prostaglandin. Based on this, a cyclooxygenase inhibition or the exercise of anti-oxidative characteristics may explain the second stage (73).

\section{$\square 15$ min $\square 30$ min $\square 45$ min $\square 60$ min}

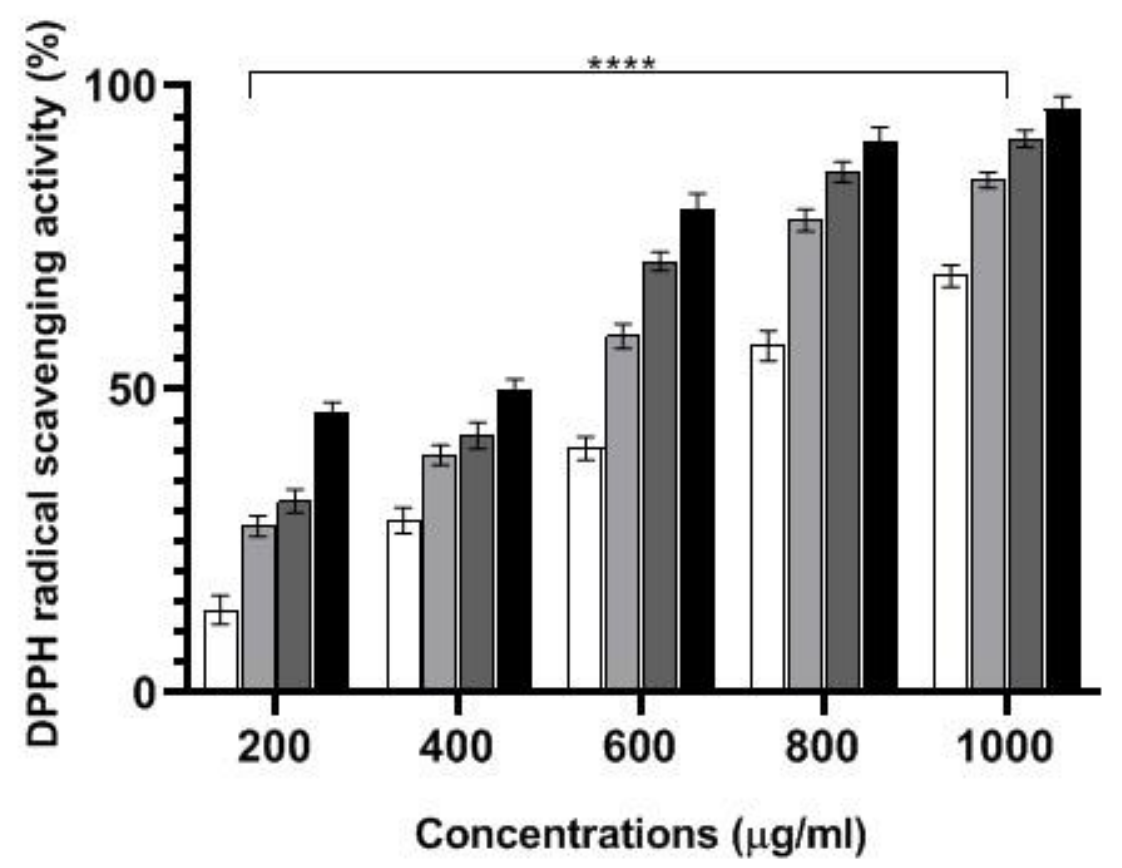

Figure 4. The DPPH radical-scavenging activities of EPS Ba3 
Table 2. Anti-inflammatory effects of EPSBa3 on carrageenan-induced hind paw edema in rats

\begin{tabular}{|c|c|c|c|c|c|}
\hline \multirow[b]{2}{*}{ Groups } & \multicolumn{5}{|c|}{ Swelling (thickness) (mm) } \\
\hline & 1 hour & 2 hours & 3 hours & 4 hours & 5 hours \\
\hline Carrageenan & $11.16 \pm 1.06^{a}$ & $15.41 \pm 1.33^{\mathrm{a}}$ & $18.21 \pm 1.12^{\mathrm{a}}$ & $18.11 \pm 1.7^{a}$ & $16.77 \pm 1.17^{\mathrm{a}}$ \\
\hline IM (10 mg/kg) & $11.19 \pm 1.03^{\mathrm{a}}$ & $14.71 \pm 1.01^{a}$ & $7.60 \pm 0.54^{b}$ & $8.81 \pm 0.76^{b}$ & $7.14 \pm 0.56^{b}$ \\
\hline EPSBa3 (50 mg/kg) & $11.08 \pm 1.05^{a}$ & $15.14 \pm 1.15^{a}$ & $12.54 \pm 1.10^{\mathrm{c}}$ & $12.24 \pm 1.07^{\mathrm{c}}$ & $10.32 \pm 0.30^{\mathrm{c}}$ \\
\hline
\end{tabular}

Values are expressed as means \pm SEM of six rats per group. Values on the same column not sharing the same superscript letters were significantly different $(\mathrm{P}<0.05)$, IM: indomethacin.

Pow tissues were analyzed for biochemical parameters such as ROS, NO, GSH and LPO (Fig. 5) and SOD and CAT operations after $5 \mathrm{~h}$ of carrageenan paw injection (Fig. 6). NO, after carrageenan therapy, the concentrations of ROS and LPO $(\mathrm{P}<0.05)$ were considerably increased in the paw tissues. However, in rats treated with carrageenan, GSH content and SOD and CAT
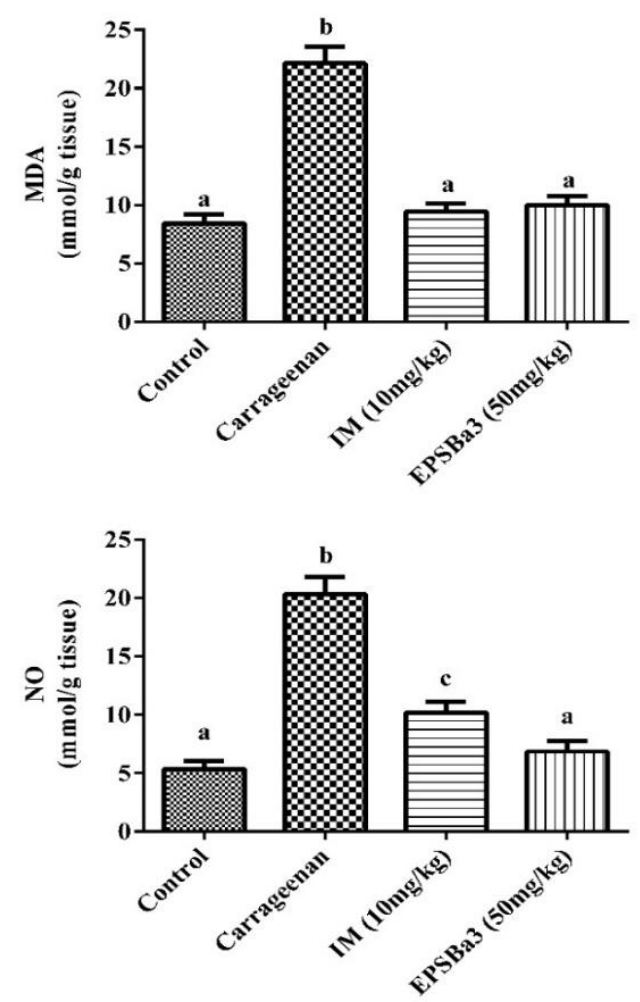

operations were reduced. Significantly improved pretreatment of EPS $(\mathrm{P}<0.05) \mathrm{NO}$, ROS and LPO, GSH and SOD and CAT (Fig. 5and 6). As shown in Fig. 7 after the injection of carrageenan, the protein expression of IL-6 was considerably improved $(\mathrm{P}<0.05)$ in the paw tissues, whereas EPSBa3 improved the expression of IL-6.
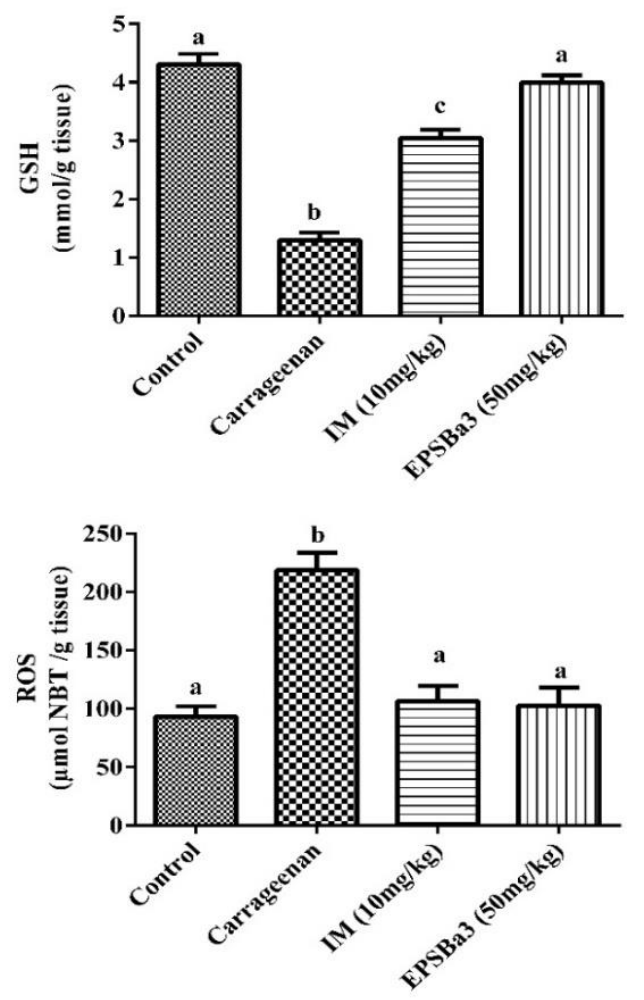

Figure 5.Effect of EPSBa3 on changes in MDA, GSH, NO and ROS levels in carrageenan-induced paw edema inrats. Values are expressed as means \pm SE of six rats per group. Values on the same column not sharing the same superscript letters were significantly different $(\mathrm{P}<0.05)$, IM: indomethacin. 

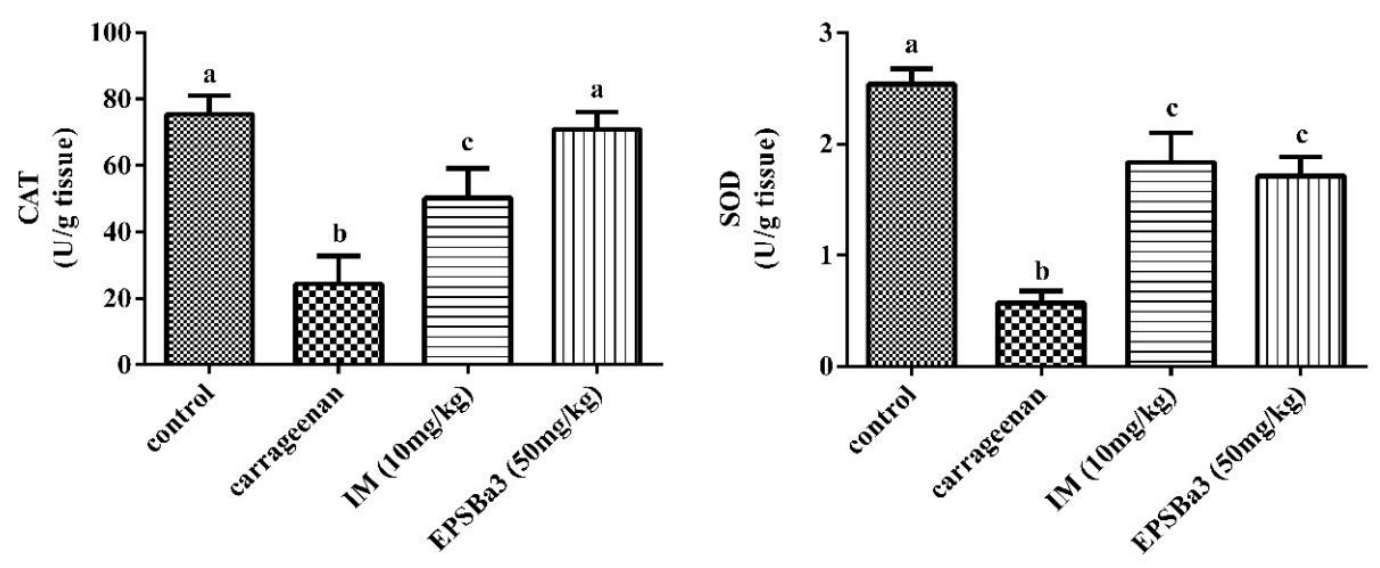

Figure 6. Effect of EPSBa3 on changes in CAT and SOD activities in carrageenan-induced paw edema inrats. Values are expressed as means $\pm \mathrm{SE}$ of six rats per group. Values on the same column not sharing the same superscript letters were significantly different $(\mathrm{P}<0.05)$, IM: indomethacin

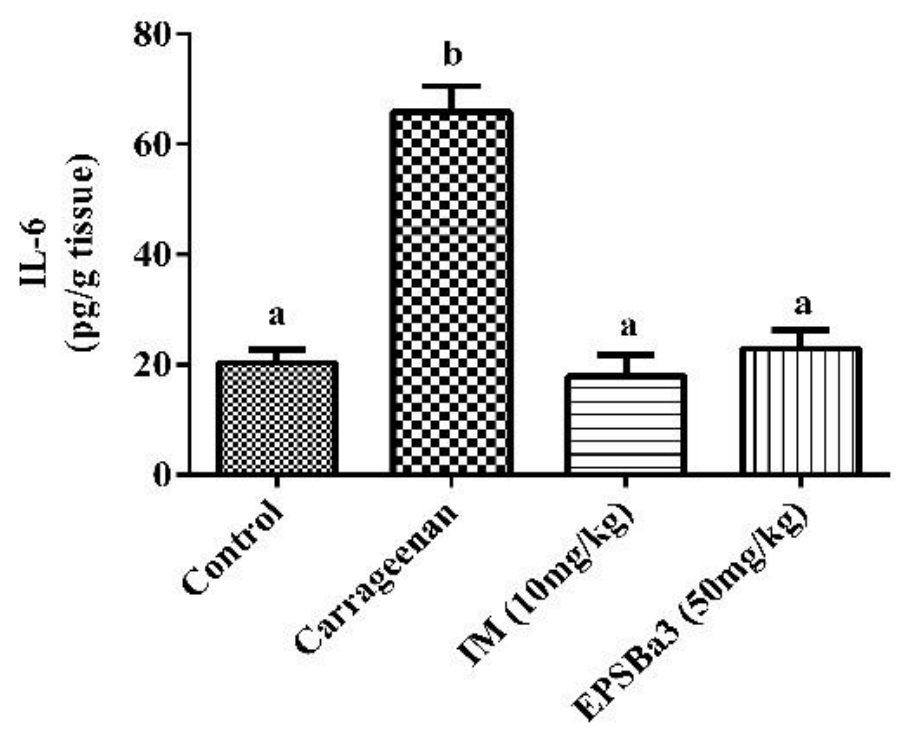

Figure 7. Effects of EPSBa3 on IL-6 protein expressions of edema paw in rats Values are expressed as means \pm SE of six rats per group. Values on the same column not sharing the same superscript letters were significantly different $(\mathrm{P}<0.05)$, IM: indomethacin. 
The antioxidant activities (SOD and CAT activities) were assessed in all-paw tissues to investigate the impacts of antioxidant defenses on the acute inflammation system. In this research, it was discovered that SOD in carrageenan-induced paw edema was enhanced by EPS in which the SOD concentration decreased considerably. Catalase is a highly reactive enzyme that reacts to water and molecular oxygen with $\mathrm{H}_{2} \mathrm{O}_{2}$ and, by donating hydrogen, can form methanol, ethanol, formic acid or phenols (74).

We found that all doses of EPS and indomethacin improved catalase activity in the current research. Our findings are in agreement with $(75,76)$ Kataoka et al. (2012) and Golechha et al., (2014) who discovered a significant reduction in catalase activity in carrageenan $(\mathrm{P}<0.001)$. The pathogenesis of inflammatory processes involves lipid peroxidation (77). In our research, lipid peroxidation (LPO) was increased in carrageenan-treated rats in accordance with Ahmed and Bastawy (2014), Ahmed and Eid (2015) (78,79). By reducing the content of LPO, EPS enhanced this impact. Antioxidant and anticancer impacts of EPS have been discovered (80). NO is a powerful vasodilator made from inducible-nitric oxide synthase that has been engaged in maintaining inflammatory reactions, including increased vascular permeability and edema through alterations in local blood flow (81) (Moncada and Higgs, 1993). Furthermore, NO can respond to peroxynitrite with superoxide anion, a powerful oxidized molecule that can cause lipid peroxidation and cell harm (82) (Rubbo et al., 1994). It is well known that the release of IL-1, IL-6, and IL-8 was stimulated by TNF- $\alpha$. IL6 improved the COX in turn. In the current research, after carrageenan injection, therapy with EPS considerably inhibited the paw edema (3-5 h). In addition, EPS considerably reduced the expressions of IL-6 proteins; this stated that EPS had antiinflammatory impacts by inhibiting IL-6 and growing antioxidant enzymes (CAT and SOD) and GSH together with reducing the content of NO, ROS and LPO. Exopolysaccharide's anti-inflammatory activity was evaluated by inhibiting macrophage production of nitric oxide (NO), inducible synthase of nitric oxide (iNOS), and5-lipoxygenase (5-LOX). This exopolysaccharide significantly $(\mathrm{p}<0.05)$ inhibited dose-dependent levels of iNOS-induced lipopolysaccharides expression in the neurons. The protective impact of EPSBa3 on oxidative stress caused by carrageenan may be due to its antioxidant activity by reducing GSH and increasing LPO and ROS. EPS separated from Micrococcus luteus (83) and Bacillus subtilis SH1 (84) has concentrationdependent DPPH radical scavenging activity.

Intense edema was produced in the carrageenan group, characterized by infiltrates of inflammatory cells as compared to the carrageenan untreated group (normal control) (Table 3). EPSBa3 $(50 \mathrm{mg} / \mathrm{kg}$ ) or indomethacin $(10 \mathrm{mg} / \mathrm{kg})$ groups treated with carrageenan there were edema decreases as well as decreases in inflammatory cell infiltration.

Table 3. Histological analyses of rats paw in the carrageenan-induced edema model

\begin{tabular}{|l|l|l|l|}
\hline \multirow{2}{*}{ Groups } & \multicolumn{2}{|l|}{ Histological score } \\
\cline { 2 - 4 } & Pannus formation & $\begin{array}{l}\text { Inflammatory cells } \\
\text { infiltration }\end{array}$ & Oedema \\
\hline Control (untreated) & - & - & - \\
\hline Carrageenan & ++ & +++ & +++ \\
\hline IM (10 mg/kg) & - & $+/+$ & $+/-$ \\
\hline EPSBa3 (50 mg/kg) & - & ++ & ++ \\
\hline
\end{tabular}

(-) no

(+) mild

$(++)$ moderate

$(+++)$ severe 


\section{Conclusion}

In conclusion, the findings showed that the Bacillus axarquiensis-isolated EPSBa3 was purified and described using several distinct analytical methods, and the EPSBa3's in vitro antioxidant property was also assessed. The EPS consisted mainly of glucuronic: mannose: galacturonic: glucose and xylose, respectively, in a molar ratio of 1:1:3:3:3 The proportion of uronic acid and sulfate was $13.9 \%$ and $7 \%$ respectively. The average molecular weight $(\mathrm{Mw})$ and molecular amount $(\mathrm{Mn})$ of FT-IR were estimated at $1.499 \times 10^{6}$ and $1.29 \mathrm{X}$ $10^{6} \mathrm{~g} / \mathrm{mol}$ respectively. The EPSBa3 had an antiinflammatory impact on paw edema induced by $\pi$ carrageenan. EPSBa3's anti-inflammatory impact may be due to a reduction in IL- 6 concentration and a reduction in NO material to avoid edema. It could also be through growing antioxidant enzyme activity (CAT and SOD), where free radicals (ROS) were scavenged and MDA levels decreased. Therefore, to avoid inflammatory diseases, EPSBa3 could be used as a source of dietary supplements.

\section{Conflict of interest}

The authors declare no conflict of interest.

\section{Financial support and sponsorship}

No funding resources to declare.

\section{References}

1-StachJE, Maldonado LA, Masson DG, Ward AC, Goodfellow M, Bull A. Statistical approaches for estimating actinobacterial diversity in marine sediments. Appl. Environ.Microbiol. 2003; 69: 61896200.

2-Lam KS. Discovery of novel metabolites from marine actinomycetes. Ind. Microbiol. 2006;9: 245251.

3-Alain K, Querellou J. Cultivating the uncultured: limits, advances and future challenges. Extremophiles. 2009;13: 583-594.

4-Bredholt H,FjaervikE, Johsen G, Ztchev, SB. Actinomycetes from sediments in Trondheim Fjord
Norway: Diversity and Biological Activity. Mar. Drugs.2008; 6(1): 12-24.

5- Ibrahim GS, Abo ElsoudMM, Asker MMS. Exopolysaccharides production and optimization by Halomonasvenusta using response surface method. BIOSCIENCE RESEARCH. 2018; 15(3): 2756-2769.

6- Altschul SF, Gish W, Miller W, Myers EW, Lipman DJ. Basic local alignment search tool.J.Mol. Biol. 1990; 215:403-10.

7- Al-Nahas MO,Darwish MM,Ali AE, Amin, MA. Characterization of an exopolysaccharideproducing marine bacterium, isolate Pseudoalteromonas $s p$. AM. Afr J. Microbiol Res., 2011;5:3823-31.

8- EL Awady ME, IbrahimGS, Ayaz NO, MouafiFE , Mahmoud MG. Production and Characterization of Bioflocculant from isolated Bacillus tequilensis MMFG37. BIOSCIENCE RESEARCH.2018; 15(4):3581-3592.

9- Ibrahim GS,Mahmoud MG, Asker MMS, Ghazy EA. Production and Biological Evaluation of Exopolysaccharide From Isolated Rhodotorula Glutinins. Australian Journal of Basic and Applied Sciences. 2012;6(3): 401-408.

10-SutherlandIW. Polysaccharases for microbial exopolysaccharides. Carbohydr. Polym.,1999; 38:319-28.

11-Lin ZB, ZhangHN. Anti- tumor and immunoregulatory activities of Ganodermalucidum and its possible mechanisms. ActaPharmacol. Sin. 2004; 25: 1387-95.

12-Manivasagam P, Sivasankar P,Venkatesan J, Senthil KK, Kim S.Production and characterization of an extracellular polysaccharide from Streptomyces violanceus MM72. Int. J. Biol. Macromol.2013; 59:29-38.

13- Wen Z, Jian Z, Yun-Yun J, Xiao Z, Xiao-Na H, Liu L, Zhen-Nai Y.Characterization and Antioxidant Activity of the Exopolysaccharide Produced by 
Bacillus amyloliquefaciens GSBa-1 J. Microbiol. Biotechnol. 2018; 28(8):1282-1292 .https://doi.org/10.4014/jmb.1801.01012 Research Article Review jmb

14- Bai Y, ZhangP, Chen G, Cao J, Huang T, Chen K. Macrophage immunomodulatory activity of extracellular polysaccharide (PEP) of Antarctic bacterium Pseudoaltermonas sp.S-5. Int Immuno pharmacol. 2012; 12:611-7.

15- Cimini D, De Rosa M,Schiraldi C. Production of glucuronic acid-based polysaccharides by microbial fermentation for biomedical applications. Biotechnol. J. 2012; 7:237-50.

16-Delbarre-Ladrat C, Sinquin C, Lebellenger L, Zykwinska A, Colliec-Jouault S. Exopolysaccharides produced by marine bacteria and their applications as glycosaminoglycan-like molecules. Front Chem. 2014; 2:1-15.

17- Rinker KD, Kelly RM. Effect of carbon and nitrogen sources on growth dynamics and exopolysaccharide production for the hyperthermophilic archae on Thermococcuslitoralis and bacterium Thermotogamaritima. Biotechnol. Bioeng. 2000; 69:537-47.

18- Poli A, Di Donato P, Abbamondi GR, Nicolaus

B. Synthesis, production, and biotechnological applications of exopolysaccharides and polyhydroxy alkanoates by Archaea. Archaea, Vol. 2011, Article ID 693253,13 pages.

19- Finore I, Di Donato P, Mastascusa V, Nicolaus B, Poli A. Fermentation technologies for the optimization of marine microbial exopolysaccharide production. Mar. Drugs. 2014; 12: 3005-24.

20- Han Y, Liu E, Liu L, Zhang B, Wang Y, Gui M, et al. Rheological, emulsifying and thermostability properties of two exopolysaccharides produced by Bacillus amyloliquefaciens LPL061. Carbohydr. Polym. 2015;115: 230-237
21- Malick A, Khodaei N, Benkerroum N, Karboune S. Production of exopolysaccharides by selected Bacillus strains: optimization of media composition to maximize the yield and structural characterization. Int. J. Biol. Macromol. 2017; 102: 539-549.

22- Du B, Lin CY, Bian ZX, Xu BJ. An insight into antiinflammatory effects of fungal beta-glucan. Trends Food Sci. Technol. 2015; 41: 49-59. doi: 10.1016/j.tifs.2014.09.002

23- Kawashima S, Hirose K, Iwata A, Takahashi K, OhkuboA, et al. $\beta$-Glucancurdlan induces IL-10producing CD4+ T cells and inhibits allergic airway inflammation. J. Immunol. 2012; 189:5713-5721. doi: 10.4049/jimmunol.1201521

24- Du B, Zeng H, Yang Y, Bian Z, Xu B. Antiinflammatory activity of polysaccharide from Schizophyllum commune as affected by ultrasonication. Int. J. Biol. Macromol. 2016; 91: 100-105. doi: 10.1016/j.ijbiomac.2016.05.052

25-Wang S, Zhou H, Feng T, Wu R, Sun X, Guan N, et al. $\beta$-Glucan attenuates inflammatory responses in oxidized LDL-induced THP-1 cells via the p38 MAPK pathway. Nutr. Metab. Cardiovasc. Dis. 2014; 24:248-255. doi: 10.1016/j.numecd.2013.09.019

26- Collins $\mathrm{CH}$, PatriciaML. Culture Methods, in CollinsandLyne's Microbiological Methods, 7th Ed. 1995; Butterworth-Heineman.

27- Ng TK, Hu WS. Adherence of emulusanproducing Acinetobactercalcoaceticus to hydrophobic liquids. Appl. Microbiol. Biotechnol. 1989; 31:480-5.

28- Yadava KL, Rahi DK, Soni SK,Rahib S. Diversity of exopolysaccharide producing fungi from foot hills of shivalik ranges of chandigarh capital region. Res. Biotechol. 2012; 3:11-18.

29- Dubois M, Gilles KA, Hamilton JK, Rebers PA, Smith F. Colorimetric method for determination of 
sugars and related substances. J. Anal. Chem. 1956; 28:350-6.

30- Holt J.G. Bergey's Manual of Systematic Bacteriology. 1st Ed., Williams and Wilkins, Baltimore U.A., . 1986; pp: 2648.

31-Gardes M, Bruns TD. ITS primers with enhanced specificity for basidiomycetes-application to the identification of mycorrhizae and rusts. Mol. Ecol. 1993; 2:113-8.

32- Tamura K, Peterson D, Peterson N, Stecher G, Nei M, Kumar S. MEGA5: Molecular evolutionary genetics analysis using maximum likelihood, evolutionary distance, and maximum parsimony methods. Molecular Biol. Evolut. 2011; 28: 2731-9.

33- Shene C, Canquil S,Rubilar M. Production of the exopolysaccharides by Streptococcus thermophilus: effect of growth conditions on fermentation kinetics and intrinsic viscosity. Int. J. Food Microbiol. 2008; 124:279-84.

34- Filisetti-Cozzi TMC,CarpitaC. Measurement of uronic acids without interference from neutral sugars. Anal. Biochem. 1991; 197:157-62.

35- Dodgson KS, Price RG. A note on the determination of the ester sulfatecontent of sulfated polysaccharides. Biochem. J. 1962; 84:106-10.

36- Sudhamani SR, Tharanathan RN, PrasadM S. Isolation and characterization of an extracellular polysaccharide from Pseudomonas caryophylli CFR 1705. Carbohydr. Polym. 2004; 56:423-7.

37- El-Sayed OH, Ismail SA, Ahmed YM, Abd ElSamei M, Asker MMS. Studies on the production of sulfated polysaccharide by locally isolated bacteria. Egypt. Pharm. J.2007; 4:439-52.

38-Jun HI, Lee H, Song GS, Kim YS. (2006). Characterization of the pectic polysaccharide from Pumpkin Peel LWT. Food Sci. Technol. 39:554-6.

39-You, L, Gao Q, Feng M, Yang B, Ren J, Gu L, Cui C, Zhao M. Structural characterization of polysaccharides from Tricholomamatsutake and their antioxidant and antitumour activities. Food Chem. 2013; 138:2242-9.

40- Ray B.Polysaccharides from Enteromorphacompressa: isolation, purification and structural features. Carbohydr. Polym. 2006; 66:408-16.

41- Winter CA, Risley EA, NussGW .Carrageenaninduced edema in hind paw of the rat as an assay for anti-inflammatory drugs. Proc. Soc. Exp. Biol. Med. 1962; 111: 544-547.

42- Bicili D, Akpinar,Kiziltunç A. Protective effect of melatonin in carrageenan-induced acute local inflammation. Pharmacological Research. 2002; 46(2): 133-139.

43- Ohkawa H, Ohnishi N, Yagi K. Assay for lipid peroxides in animal tissues by thiobarbituric acid reaction. Anal Biochem. 1979; 9: 351-358.

44- Vrablic AS, Albright CD, Craciunescu CN, Salganik RI, Zeisel SH. Altered mitochondrial function and over generation of reactive oxygen species precede the induction of apoptosis by 1-Ooctadecyl-2-methyl-rac-glycero-3-phosphocholine in p53-defective hepatocytes. FASEB J. 2001; 15:17391744.

45- Wang CC, Huang YJ, Chen LG, Lee LT, Wang LL .Inducible nitric oxide synthase inhibitors of Chinese herbs III. Rheum palmaturn. PlantaMedica. 2002; 68 (10): 869-874.

46- Beutler E, Duron O, Kelly BM. J Lab Clin Med. 1963; 61: 882-890.

47- Minami M, Yoshikawa H. A simplified assay method of superoxide dismutase activity for clinical use. ClinicaChimicaActa. 1979; 92: 337-342.

48- AebiH.Catalase. In: Methods in Enzymatic Analysis. Bergmeyer HU (ed); Chemic. Academic Press; Inc. Verlag. 1979; 2: 673-678. 
49- GuoS , Mao W, HanY, Zhang, Yang C, ChenY,ChenY, Xu J, Li H, Qi X, XuJ. Structural characteristics and antioxidant activities of the extracellular polysaccharides produced by marine bacterium Edwardsiellatarda.Bioresource Technology. 2010; 101(12): 4729-4732.

50- SmiderleFR, Olsen LM, CarboneroER, Marcon R, Baggio CH, Freitas CS, Santos ARS, TorriG,Gorin PAJ, Iacomini M. Phytochemistry. 2008;69 :2731-2736.

51- Silveiraa B, Marcia LL , Fhernanda RS, Franciane A, Eduardo MP,Mariane BC, Elisabeth W, Andréa C R,Guilherme LS, Thales RC, Sandra AF, Marcello I. Exopolysaccharide produced by Pleurotussajor-caju: Its chemical structure and antiinflammatory activity. International Journal of Biological Macromolecules. 2015;75:90-96.

52- Kumar CG, Han-Seung J, Jang-Won C, YoonMoo K, Chung-Soon C. Purification and characterization of an extracellular polysaccharide from haloalkalophilic Bacillus sp. I-450. Enzyme Microbial Technol. 2004; 34:7673-81.

53-Béjar B, Llamas I, Calvo C, Quesada E. Characterization of exopolysaccharides produced by 19 halophilic strains of the species Halomonaseurihalina. J. Biotechnol. 1998; 61: 13541.

54- Arias S, Del Moral A, Ferrer MR, Tallon R, Quesada E,Béjar V. Mauran an exopolysaccharide produced by the halophilic bacterium Halomonasmaura, with a novel composition and interesting properties for biotechnology. Extremophiles. 2003; 7: 319-26.

55-Mata JA, Béjar V, Llamas I, Arias S, Bressollier P, Tallon R, Urdaci MC, Quesada E. Exopolysaccharides produced by the recently described bacteria Halomonasventosae and Halomonasanticariensis. Res. Microbiol. 2006; 157 : 827-35.
56- Mata JA, Béjar V, Bressollier P, Tallon R, Urdaci MC, QuesadaE, Llamas I. Characterization of exopolysaccharides produced by thres moderately halophilic bacteria belonging to the family Alteromonadaceae. J. Appl. Microbiol. 2008; 105: 521-8.

57- Matou S, Colliec-Jouault S, Galy-Fauroux I, Ratiskol J, Sinquin C, Guezennec J, Fischer AM,Helley D. Effect of an over sulfated exopolysaccharide on angiogenesis induced by fibroblast growth factor-2 or vascular endothelial growth factor in vitro. Biochem. Pharmacol. 2005; 69: 751-9.

58-Arena A, Gugliandolo C, Stassi G, Pavone B, Iannello D, Bisignano G,Maugeri TL. An exopolysaccharide produced by Geobacillus thermodenitrificans strain B3-72: antiviral activity on immune competent cells. Immunol. Lett. 2009;123:132-7.

59-Mota R, Guimaraes R, Buttel Z, Rossi F,Colica G. Production and characterization of extracellular carbohydrate polymer from Cyanothece sp. CCY 0110. Carbohydr. Polym. 2013;92: 1408-15.

60-Ozturk S, Aslim B, Suludere Z, Tan S. Metal removal of cyanobacterial exopolysaccharides by uronic acid content and monosaccharide composition. Carbohydr.Polym. 2014 ; 101: 265-71.

61-KhattarJIS, Singh DP, JindalN, Kaur N, Singh Y, Rahi P, Gulati A. Isolation and characterization of exopolysaccharides produced by the cyanobacterium Limnothrixredekei PUPCCC 116. Applied Biochem. Biotechnol. 2010; 162: 1327-38.

62- Zou C, DuY, Li Y, Yang, J, FengT, Zhang L, Kennedy JF. Preparation of lacquer polysaccharide sulfates and their antioxidant activity in vitro. Carbohydr. Polym. 2008; 73: 322-31.

63- Cheng A, Wan F, Jin Z, Wang J,Xu X. Nitrite oxide and inducible nitric oxide synthase were regulated by polysaccharides isolated from 
GlycyrrhizauralensisFisch.

Ethnopharmacol.2008; 118: 59-64.

64- Zhao TT, Zhang QB, Qi HM, Zhang H,Niu XZ, Xu ZH. Int. J. Biol. Macromol. 2006;38(1):45-50.

65- Seng Y H, Yang J H, Mau J L. Food Chem. 2008; 107(2):732-738.

66- Asker M M S, Ahmed Y M, Ramadan M F.Carbohydrate Polym. 2009; 77: 563-567.

67- Zhang Q, Li N, Liu X, Zhao Z, Li Z, Xu Z, Carbohydrate Res. 2004; 339(1):105-111.

68- Iwalewa EO, McGaw LJ, Naidoo V, Eloff JN. Inflammation: the foundation of diseases and disorders. A review of phytomedicines of South African origin used to treat pain and inflammatory conditions. Afr. J. Biotechnol. 2007; 6: 2868-2885.

69- Mueller M, Hobiger S, Jungbauer A. Antiinflammatory activity of extracts from fruits, herbs and spices. Food Chem. 2010; 122: 987-996.

70- Guay J, Bateman K, Gordon R, ManciniJ ,Riendeau D. Carrageenan-induced paw edema in rat elicits a predominant Prostaglandin E2 (PGE2) response in the central nervous system associated with the induction of microsomal PGE 2 Synthase-1. The Journal of Biological Chemistry. 2004; 279: 24866-24872.

71- Ialenti A, Ianaro A, Moncada S, Di Rosa M. Modulation of acute inflammation by endogenous nitric oxide. Eur. J. Pharmacol. 1995; 211: 177-182.

72- Heller A, Koch T, Schmeck J,Ackern KV. Lipid mediators in inflammatory disorders. Drugs. 1998;554: 487-496.

73- Salvemini D, Wang ZQ, Wyatt P, Bourdon DM, Marino MH, Manning PT, Currie MG Nitric oxide: a key mediator in the early and late phase of carrageenan-induced rat paws inflammation. Br. J. Pharmacol. 1996; 118: 829-838.
J. 74- Matés JM, Sánchez-Jiménez F. Antioxidant enzymes and their implications in pathophysiologic processes. Front. Biosc. 1999; 4: 339-345.

75-Kataoka T, Teraoka J, Sakoda A, Nishiyama Y, Yamato K, Monden M, Ishimori $\mathrm{Y}$, Nomura $\mathrm{T}$, Taguchi T, Yamaoka K. Protective effects of radon inhalation on carrageenan-induced inflammatory paw edema in mice. Inflammation. 2012; 35(2):71322.

76-Golechha M, Sarangal V, Ojha S, Bhatia J, Arya DS. Anti-inflammatory effect of Emblicaofficinalis in rodent models of acute and chronic inflammation: Involvement of possible mechanisms. International Journal of Inflammation. 2014; 1-6

77- Agha AM, Gad MZ. Lipid peroxidation and lysosomal integrity in different inflammatory models in rats: the effects of indomethacin and naftazone. Pharmacol. Res. 1995; 32(5): 279-285.

78- Ahmed MM, Bastawy S. Evaluation of antiinflammatory properties and possible mechanism of action of Egyptian quince (Cydoniaoblonga) leaf. The Egyptian Journal of Biochemistry \& Molecular Biology. 2014; 32 (2): 190-205.

79- Ahmed MM,Eid MM. Evaluation of Balanitesaegyptiaca Oil as Untraditional Source of Oil and its Anti-Inflammatory Activity. J. Drug Res. Egypt. 2015;36 (1):1-11.

80- Ahmed MM, Manal G Mahmoud, Manal S Selim, and EL Awady ME.Exopolysaccharide from Marine Bacillus velezensis MHM3 Induces Apoptosis of Human Breast Cancer MCF-7 Cells through a Mitochondrial Pathway. Asian Pac J Cancer Prev. 2018; 19(7): 1957-1963.

81- Moncada S, Higgs A. The L-arginine-nitric oxide pathway. N. Engl. J. Med.1993;329: 2002-2012.

82- Rubbo H, Radi R, Trujillo M, Telleri R, Kalyanaraman B, Barnes S, Kirk M,Freeman BA Nitric oxide regulation of superoxide and 
peroxynitrite-dependent lipid peroxidation. J. Biol. Chem. 1994;269(42): 26066-26075.

83- Asker MMS, EL Sayed OH, Manal G Mahmoud, Ramadan MF. Chemical structure and antioxidant activity of a new exopolysaccharide produced from Micrococcus luteus. Journal of Genetic Engineering and Biotechnology. 2014; 12: 121-126.
84- Hassan SWM, Ibrahim HAH. Production, Characterization and Valuable Applications of Exopolysaccharides from Marine Bacillus subtilis SH1. Polish Journal of Microbiology. 2017; 66 (4): 449-461. 
